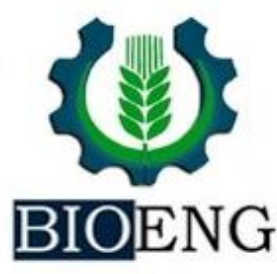

\title{
MONITORAMENTO E REMOÇÃO DE METAIS EM UM \\ REATOR ANAERÓBIO APLICADO AO TRATAMENTO DE DRENAGEM ÁCIDA DE MINA
}

Lauren N. M. Yabuki ${ }^{1 *}$, Elis Watanabe Nogueira², Márcia H. R. Z. Damianovic $^{2}$, Amauri A. Menegário ${ }^{3}$, Marcelo L. Garcia ${ }^{1}$

${ }^{1}$ Universidade Estadual Paulista (UNESP), Instituto de Geociências e Ciências Exatas (IGCE), Av. 24 A, 1515 - Bela Vista, 13506-900, Rio Claro, SP, Brasil

${ }^{2}$ Universidade de São Paulo (USP), Laboratório de Processos Biológicos (LPB), Escola de Engenharia de São Carlos (EESC), Av. João Dagnone, 1100 - Santa Angelina, Bloco 4-F, 13.563-120, São Carlos, SP, Brasil

${ }^{3}$ Universidade Estadual Paulista (UNESP), Centro de Estudos Ambientais (CEA), Av. 24 A, 1515 - Bela Vista, 13506-900, Rio Claro, SP, Brasil

Article history: Received 14 October 2020; Received in revised form 19 November 2020; Accepted 20 November 2020; Available online 30 December 2020.

\section{RESUMO}

Uma forma eficiente de tratar efluentes provindos de drenagem ácida de mina (DAM), frente aos tratamentos convencionais de neutralização da acidez, é por meio da aplicação de processos biológicos anaeróbios que utilizam bactérias redutoras de sulfato (BRS) apresentando remoção de sulfato, alcalinização do meio e precipitação de metais. O presente trabalho teve como objetivo o monitoramento da concentração total dos metais $\mathrm{Co}, \mathrm{Cu}, \mathrm{Fe}$, Mn, Mo, Ni, Se, V, W e Zn e a avaliação das respectivas eficiências de remoção destes metais em um reator de leito fixo-estruturado e fluxo descendente (DFSBR), utilizado para tratar efluentes oriundos de DAM sintética rica em sulfato. A digestão anaeróbia empregada para o tratamento de DAM obteve um elevado desempenho com eficiências médias de remoção, nas Fases de II a IV, de $92 \pm 4,87 \pm 8,71 \pm 21,61 \pm 24,92 \pm 4$ e $86 \pm 8$ para $\mathrm{Co}, \mathrm{Cu}, \mathrm{Fe}, \mathrm{Mn}, \mathrm{Ni}$ e Zn, respectivamente. O tratamento anaeróbico de DAM pelo reator DFSBR revela-se como uma alternativa promissora para a remoção de metais, além da redução de sulfato e elevação do $\mathrm{pH}$, de acordo com as condições descritas neste estudo, e uma opção promissora e complementar para a remoção de manganês, comumente considerado de difícil remoção em DAMs reais, empregando processos físico-químicos convencionais.

Palavras-chave: Drenagem ácida de mina (DAM). Tratamento biológico. Remoção de metais.

\section{MONITORING AND REMOVAL OF METALS FROM ACID MINE DRAINAGE THROUGH AN ANAEROBIC REACTOR}

\begin{abstract}
An efficient way to treat effluents from acid mine drainage (AMD), compared to conventional acid neutralization treatments, is through the application of anaerobic biological processes that use sulfate reducing bacteria (BRS) presenting sulfate removal, alkalinization of the
\end{abstract}

\footnotetext{
*lauren.yaduki@unesp.br
} 
medium and metal precipitation. An efficient way to treat this type of effluent, compared to conventional acidification-neutralization process, is by applying anaerobic biological processes that use sulphate-reducing bacteria (SRB) presenting sulphate removal, medium alkalinization and metal precipitation. The present study aimed to monitor the total concentration of $\mathrm{Co}, \mathrm{Cu}, \mathrm{Fe}, \mathrm{Mn}, \mathrm{Mo}, \mathrm{Ni}, \mathrm{Se}, \mathrm{V}, \mathrm{W}$ and $\mathrm{Zn}$ and to evaluate their metal removal efficiencies in a Down-Flow Fixed-structured Bed Reactor (DFSBR), used to treat effluents from sulfate-rich synthetic AMD. The anaerobic process for the AMD treatment has obtained a high performance with average removal efficiencies, from Phases II to IV of $92 \pm$ 4, $87 \pm 8,71 \pm 21,61 \pm 24,92 \pm 4$ e $86 \pm 8$ for $\mathrm{Co}, \mathrm{Cu}, \mathrm{Fe}, \mathrm{Mn}, \mathrm{Ni}$ and $\mathrm{Zn}$, respectively. The anaerobic treatment of AMD by the DFSBR reactor proves to be a promising alternative for the metal removal besides sulfate reduction and $\mathrm{pH}$ elevation, according to the conditions described in this study, and a promising and complementary option for the Mn removal, considered problematic as generally is not efficiently removed in real MADs, using conventional physicochemical processes.

Keywords: Acid mine drainage (AMD). Biologic treatment. Metal removal.

\section{INTRODUÇÃO}

Ao longo dos anos, o impacto ocasionado pela exploração de minas ativas e inativas tem gerado, um grave problema ambiental relacionado com a drenagem da água proveniente das atividades de mineração (CAMPBELL, 1995). A exposição de minerais sulfetados (principalmente pirita - $\mathrm{FeS}_{2}$, entre outros como arsenopirita - AsFeS, calcopirita $\mathrm{CuFeS}_{2}$, galena - PbS, esfalerita - ZnS e cinábrio - $\mathrm{HgS}$ ) à água e oxigênio atmosférico ocasiona a oxidação de sulfetos metálicos (BENSON et al., 2013). A oxidação dos sulfetos possibilita a formação de ácido sulfúrico, aumentando a acidez do meio e favorecendo a solubilização de metais provindos das matrizes rochosas, gerando a drenagem ácida de mina (DAM) que percola as áreas de disposição de resíduos (MELLO et al., 2014). O processo de oxidação dos sulfetos metálicos também pode ser acelerado e intensificado por bactérias (principalmente a Acidithiobacilus ferroxidans) atuantes principalmente quando o $\mathrm{pH}$ da água atinge valores inferiores a 3,5 (BAKER \& BANFIELD, 2003). Portanto, as águas provindas da DAM são caracterizadas por $\mathrm{pH}$ baixo e altas concentrações de metais (principalmente $\mathrm{Al}, \mathrm{Fe}$ e $\mathrm{Mn}$ ), metaloides (As) e metais traço (como $\mathrm{Cd}, \mathrm{Cu}, \mathrm{Ni}, \mathrm{Zn}$ ) que podem contaminar severamente águas superficiais e subterrâneas, bem como solos (AKCIL \& KOLDAS, 2006).
Diante da problemática envolvendo a DAM, é de fundamental importância o controle por órgãos fiscalizadores referente ao tratamento deste tipo de efluente. Os tratamentos disponíveis para mitigar os impactos causados pela DAM consistem em processos físico-químicos e biológicos. Esses processos dividem-se ainda em processos ativos e passivos (onde o diferencial entre os tratamentos, é a introdução ou não de energia no sistema para início e continuação do processo) (BLOWES et al., 2003). O tratamento mais convencional é o físico-químico que envolve a neutralização da acidez, com a adição de compostos alcalinos (entre os mais utilizados o calcário - $\mathrm{CaCO}_{3}$, a cal virgem - $\mathrm{CaO}$ ou a hidratada $-\mathrm{Ca}(\mathrm{OH})_{2}$ e hidróxido de sódio - $\mathrm{NaOH}$ ) com a consequente elevação do $\mathrm{pH}$ e precipitação de metais e metaloides sob a forma de hidróxidos e carbonatos (JOHNSON; HALLBERG, 2005). As desvantagens desta tecnologia envolvem a necessidade de grandes doses de material alcalino para elevação do $\mathrm{pH}$, a produção de grandes quantidades de lodo, que devem ser dispostas de maneira adequada tornando o sistema de tratamento de alto custo, além da baixa eficiência de remoção de sulfatos se comparados aos tratamentos biológicos (GARCIA et al., 2001).

Os sistemas de tratamento biológico anaeróbio têm se tornado uma alternativa 
altamente viável visto que as altas concentrações de sulfato presente nas DAM permitem a oxidação da matéria orgânica, por meio das bactérias redutoras de sulfato (BRS), que utilizam o íon $\mathrm{SO}_{4}{ }^{2-}$, presente em altas concentrações nas DAMs, produzindo sulfeto de hidrogênio $\left(\mathrm{H}_{2} \mathrm{~S}\right)$ e alcalinidade $\left(\mathrm{HCO}_{3}{ }^{-}\right)$(GODOI et al., 2017; UCAR et al., 2011; GALLEGOS-GARCIA et al., 2009). O sulfeto de hidrogênio que apresenta odor desagradável e características tóxicas e corrosivas, posteriormente, reage com os metais também encontrados em elevadas concentrações nas DAMs, formando sulfetos metálicos insolúveis, que precipitam e podem ser separados da fase líquida e submetidos a processos físicoquímicos para recuperação dos metais de interesse (KEFFENI et al., 2015; SAHINKAYA \& GUNGOR, 2010; SHEORAN et al., 2010). Outros processos biológicos como por exemplo: a biossorção, metilação combinada com volatilização, complexação também são capazes de remover metais de águas

\section{MATERIAIS E MÉTODOS Metodologia Analítica}

Amostras de afluente, efluente e descarte de fundo foram coletadas diretamente do biorreator, colocadas em recipientes plásticos, acidificados com $\mathrm{HNO}_{3} 2 \%$ e armazenadas a $4^{\circ} \mathrm{C}$ até serem digeridas e analisadas. $\mathrm{O}$ reator foi operado no Laboratório de Processos Biológicos (LPB / EESC / USP), descrito por Nogueira et al. (2018). Análises físicoquímicas foram realizadas de acordo com o protocolo descrito em Standard Methods for the Examination of Water and Wastewater (APHA/AWWA/WEF, 2005).

A digestão das amostras e análises multielementares por Espectroscopia de Emissão Ótica por Plasma Indutivamente Acoplado (ICP OES) foram realizadas no Instituto de Geociências e Ciências Exatas e Centro de Estudos Ambientais (IGCE/CEA/UNESP, Rio Claro/SP).

$\mathrm{O}$ procedimento de digestão ácida em sistema aberto por bloco aquecedor foi residuárias, porém o tratamento biológico por meio das BRS, se destaca ao combinar a remoção da acidez, sulfato e metais (KAKSONEN \& PUHAKKA, 2007). Além disso, o tratamento biológico é economicamente mais viável quando comparado aos processos físico-químicos, uma vez que apresenta custos de instalação e operação relativamente mais baixos, requer menores áreas para disposição do lodo gerado e ainda pode haver a geração de biogás (LEWIS, 2010).

Diante da problemática descrita acima acerca da DAM, este trabalho teve como objetivo monitorar a concentração total dos elementos-traço (cobalto, cobre, ferro, manganês, molibdênio, níquel, selênio, tungstênio, vanádio e zinco), nas correntes de entrada, saída e descarte de fundo, e avaliar as respectivas eficiências de remoção, em um biorreator sob tratamento de drenagem ácida de mina sintética simulando as concentrações de sulfato e metais comumente encontradas em DAMs reais.

adaptado por Dimpe et al. (2014) e Krug et al. (2016). $10 \mathrm{~mL}$ de amostra de DAM sintética foram colocados em um tubo macro de borosilicato de vidro. Uma mistura ácida de água régia $\left(\mathrm{HCl}+\mathrm{HNO}_{3}\right.$, 3: 1) foi adicionada e a mistura foi deixada overnight à temperatura ambiente para uma prévia digestão. Em seguida, as amostras foram digeridas em um bloco aquecedor até a temperatura de $150{ }^{\circ} \mathrm{C}$ por 4 a 6 horas. Os tubos de digestão foram cobertos para reduzir a perda de analito devido à vaporização da amostra. Após arrefecimento até à temperatura ambiente, a solução foi transferida para tubos de centrífuga de polipropileno e diluídas para 30 - $50 \mathrm{ml}$ com água ultrapura.

As amostras foram digeridas em duplicata e para fins de validação do método foram digeridas também amostras de branco do método (porção de água ultrapura processada exatamente como a 
amostra, incluindo exposição a todo equipamento, vidraria, procedimentos $\mathrm{e}$ reagentes), branco fortificado/spike (branco do método contendo todos os mesmos reagentes e preservativos como as amostras, no qual uma concentração conhecida dos analitos é adicionada) e amostra fortificada/spike (porção adicional de uma amostra na qual, antes do seu processamento, são adicionadas quantidades conhecidas dos analitos de interesse) (ZHANG, 2007).

A concentração total dos metais foi analisada por meio da Espectroscopia de Emissão Ótica por Plasma Indutivamente Acoplado (ICP OES) (iCAP 6000 Series, Thermo Scientific, EUA)._As condições operacionais do espectrômetro ICP OES estão descritas a seguir: potência de rádiofrequência RF: $1300 \mathrm{~W}$; configuração da tocha: vista axial; vazão do gás de plasma: 10 L.min ${ }^{-1}$; vazão do gás auxiliar: 0,5 L.min ${ }^{-1}$; vazão do gás de nebulização: 0,75 L. $\min ^{-1}$; taxa de aspiração da amostra: 3,0 mL.min ${ }^{-1}$; câmara de nebulização: ciclônica; nebulizador: V-groove; replicata: três. Os metais analisados com seus respectivos comprimentos de onda foram os seguintes: Co 228,6 nm; Cu 324,7 nm; Fe 259,9 nm; Mn 257,6 nm; Mo 202,0 nm; Ni 231,6 nm; Se 196,026 nm; V 309,3 nm; W 224,9 nm e Zn 213,8 nm. Cada curva de calibração foi preparada com a respectiva matriz utilizada no procedimento de extração/digestão. Os limites de detecção (calculados como a média mais três vezes o desvio padrão dos valores do branco analítico) foram 0,$4 ; 2,0$; 3,$8 ; 1,6 ; 0,5 ; 0,5 ; 3,0 ; 1,7 ; 1,9$ e 0,3 para $\mathrm{Co}, \mathrm{Cu}, \mathrm{Fe}, \mathrm{Mn}, \mathrm{Mo}, \mathrm{Ni}, \mathrm{Se}, \mathrm{V}, \mathrm{W}$ e $\mathrm{Zn}$, respectivamente. As concentrações de molibdênio, selênio, vanádio e tungstênio não foram quantificadas (os valores apresentaram-se abaixo do limite de detecção) em ambas correntes de entrada e saída do reator. Amostras fortificadas com solução padrão multielementar foram usadas para verificar a precisão analítica (HARRIS, 2007).

\section{Configuração experimental}

$\mathrm{O}$ reator de leito fixo-estruturado e fluxo descendente (Down-Flow FixedStructured Bed Reactor - DFSBR) está descrito em Nogueira et al. (2018), com volume útil de $2,2 \mathrm{~L}$, mantido à temperatura de $30^{\circ} \mathrm{C}$ e tempo de detenção hidráulica (TDH) de $19 \pm 2$ horas por um período de operação de 229 dias. O material suporte consistiu de cilindros de polietileno de baixa densidade com $30 \mathrm{~mm}$ de comprimento e $25 \mathrm{~mm}$ de diâmetro cada, dispostos em quatro hastes na coluna central. A inoculação do reator foi realizada com lodo proveniente de um reator UASB tratando vinhaça de cana-deaçúcar visando à produção de metano. $\mathrm{O}$ processo de inoculação do reator foi o mesmo utilizado por Godoi et al. (2017), através da recirculação do lodo na zona de sedimentação até a verificação da adesão da biomassa ao material suporte.

A água residuária sintética foi preparada para simular uma típica drenagem ácida de mina rica em sulfato (concentração de sulfato da ordem de 2000 mg. $\mathrm{L}^{-1}$ ) com dosagens adicionais de sulfato de sódio $\left(\mathrm{Na}_{2} \mathrm{SO}_{4}\right)$, sulfato de alumínio hidratado $\left(\mathrm{Al}_{2}\left(\mathrm{SO}_{4}\right)_{3} \cdot 16 \mathrm{H}_{2} \mathrm{O}\right)$, cloreto de magnésio hexahidratado $\left(\mathrm{MgCl}_{2} \cdot 6 \mathrm{H}_{2} \mathrm{O}\right)$, fosfato de sódio monobásico monohidratado $\left.\left(\mathrm{NaH}_{2} \mathrm{PO}_{4} \cdot \mathrm{H}_{2} \mathrm{O}\right)\right)$, cloreto de amônio $\left(\mathrm{NH}_{4} \mathrm{Cl}, 58 \mathrm{mg} . \mathrm{L}-1\right)$ e fosfato de potássio monobásico $\left(\mathrm{KH}_{2} \mathrm{PO}_{4}, 56\right.$ mg.L-1) no início de cada ciclo operacional.

Os reagentes químicos utilizados para a suplementação dos metais $\mathrm{Co}, \mathrm{Cu}, \mathrm{Fe}$, $\mathrm{Mn}, \mathrm{Ni}$ e $\mathrm{Zn}$ nas Fases II, III e IV foram: cloreto de cobalto dihidratado $\left(\mathrm{CoCl}_{2} .2 \mathrm{H}_{2} \mathrm{O}\right.$, com adições de 2,6 e 10 mg. $\mathrm{L}^{-1}$ nas Fases II, III e IV, respectivamente); sulfato de cobre pentahidratado $\left(\mathrm{CuSO}_{4} .5 \mathrm{H}_{2} \mathrm{O}\right.$, com adições de 1,3 e 5 mg. $\mathrm{L}^{-1}$ ); sulfato ferroso heptahidratado $\left(\mathrm{FeSO}_{4} .7 \mathrm{H}_{2} \mathrm{O}\right.$, com adições de 30,70 e 110 mg. $\mathrm{L}^{-1}$ ); sulfato de manganês monohidratado $\left(\mathrm{MnSO}_{4} \cdot \mathrm{H}_{2} \mathrm{O}\right.$, com adições de 6,8, 18,8 e 30,8 mg. $\mathrm{L}^{-1}$ ); cloreto de níquel hexahidratado $\left(\mathrm{NiCl}_{2} .6 \mathrm{H}_{2} \mathrm{O}\right.$, com adições de 2,6 e 10 mg. $\left.\mathrm{L}^{-1}\right)$ e cloreto de zinco $\left(\mathrm{ZnCl}_{2}\right.$, com 
adições de 5,$7 ; 13,7$ e 21,7 mg. $\left.\mathrm{L}^{-1}\right)$. As adições destes reagentes químicos resultaram nas concentrações apresentadas na Tabela 1, ressaltando que na Fase I, na qual não houve a suplementação dos metais, as concentrações dos metais Co, $\mathrm{Cu}, \mathrm{Fe}, \mathrm{Mn}, \mathrm{Ni}$ e $\mathrm{Zn}$ podem ter origem da vinhaça que foi adicionada ao reator como fonte de carbono e elétrons (DQO solúvel média de $\left.3800 \pm 800 \mathrm{mg} \cdot \mathrm{L}^{-1}\right)$. A concentração de sulfato foi variável entre 1000 a $3000 \mathrm{mg} \cdot \mathrm{L}^{-1}$. A suplementação dos metais foi adicionada ao longo do período de operação do reator, de forma gradativa (a partir do $116^{\circ}$ dia), de forma a não provocar um choque de carga para a população microbiana presente (Tabela 1 , Fases II, III e IV).

\section{Análise Estatística}

A fim de verificar diferenças estatísticas entre as eficiências de remoção dos metais $\mathrm{Co}, \mathrm{Cu}, \mathrm{Fe}, \mathrm{Mn}, \mathrm{Ni}$ e $\mathrm{Zn}$ na Fase I (sem suplementação de metais) e durante as Fases II, III e IV (com suplementação de metais) foram realizadas análises estatísticas por meio da análise de variância (ANOVA de fator único), com significância de 5\%. Adicionalmente, um gráfico Box-Plot foi construído a fim de representar as eficiências de remoção dos metais analisados no presente estudo, utilizando valores de mediana, média \pm desvio padrão como limites das caixas, limites inferiores e superiores.

Tabela 1. Composição da DAM sintética em relação aos metais adicionados $\left(\mathrm{mg}^{\mathrm{L}} \mathrm{L}^{-1}\right) \mathrm{e}$ comparação com dados da literatura

\begin{tabular}{|c|c|c|c|c|c|}
\hline Fase & I & II & III & IV & \multirow{2}{*}{$\begin{array}{c}\text { Valores máximos } \\
\text { encontrados } \\
\text { na literatura de DAMs } \\
\text { reais }^{1,2}\end{array}$} \\
\hline Dias & $1-115$ & $116-155$ & $156-175$ & $176-229$ & \\
\hline Co & $0,006 \pm 0,001$ & $3,2 \pm 0,1$ & $6,0 \pm 0,5$ & $14 \pm 2$ & 10 \\
\hline $\mathbf{C u}$ & $0,03 \pm 0,01$ & $2,1 \pm 0,1$ & $4,4 \pm 0,3$ & $11,0 \pm 0,3$ & 64 \\
\hline $\mathbf{F e}$ & $6,3 \pm 0,5$ & $16,3 \pm 0,2$ & $54 \pm 1$ & $218 \pm 2$ & 323 \\
\hline Mn & $0,5 \pm 0,3$ & $4,3 \pm 0,1$ & $20 \pm 4$ & $24,8 \pm 0,1$ & 91 \\
\hline $\mathbf{N i}$ & $0,006 \pm 0,004$ & $3,9 \pm 0,1$ & $8 \pm 1$ & $17,2 \pm 0,3$ & 10 \\
\hline Zn & $1,71 \pm 0,04$ & $9,4 \pm 0,1$ & $17 \pm 4$ & $30 \pm 4$ & 124 \\
\hline
\end{tabular}

${ }^{1}$ Cánovas et al. (2018); ${ }^{2}$ Campaner, Luiz-Silva e Machado (2014).

\section{RESULTADOS E DISCUSSÃO}

As concentrações de Mo, Se, V e W não foram quantificadas (os valores apresentaram-se abaixo do limite de detecção) em ambas as correntes do reator. As concentrações totais dos metais $\mathrm{Co}, \mathrm{Cu}$, $\mathrm{Fe}, \mathrm{Mn}$, Ni e $\mathrm{Zn}$ foram determinadas nas correntes de entrada (Tabela 1) e saída do reator (Figura 1 e Tabela 2).

A suplementação de metais resultou na seguinte faixa de concentração na entrada do reator (Tabela 1): $0,006-14$;
$0,03-11,0 ; 6,3-218,0 ; 0,5-24,8 ; 0,006$ - 17,2 e $1,7 \quad-\quad 30,0 \quad$ mg. $\mathrm{L}^{-1}$, respectivamente, para $\mathrm{Co}, \mathrm{Cu}, \mathrm{Fe}, \mathrm{Mn}, \mathrm{Ni}$ e Zn. Os intervalos de concentrações obtidos com a suplementação abrangem os valores reais dos metais em DAMs reais no Brasil e Espanha. 
Tabela 2. Concentrações totais efluente de $\mathrm{Co}, \mathrm{Cu}, \mathrm{Fe}, \mathrm{Mn}, \mathrm{Ni}$ e Zn (mg. $\mathrm{L}^{-1}$ )

\begin{tabular}{|c|c|c|c|c|c|c|c|c|c|c|c|c|}
\hline \multirow{2}{*}{$\begin{array}{c}\begin{array}{c}\text { Fases do } \\
\text { reator }\end{array} \\
\text { Dias de } \\
\text { operação }\end{array}$} & \multirow{2}{*}{$\begin{array}{c}\text { I } \\
(1-115)\end{array}$} & \multicolumn{4}{|c|}{ II $(116$ - 155) } & \multicolumn{2}{|c|}{ III $(156-175)$} & \multicolumn{4}{|c|}{ IV (176-229) } & \multirow{2}{*}{$\begin{array}{l}\text { Legisl } \\
\text { ação }\end{array}$} \\
\hline & & 126 & 135 & 142 & 155 & 173 & 175 & 190 & 202 & 223 & 229 & \\
\hline Co & $\begin{array}{c}0,002 \pm \\
0,001\end{array}$ & $\begin{array}{c}0,4 \pm \\
0,1\end{array}$ & $\begin{array}{c}0,16 \pm \\
0,01\end{array}$ & $\begin{array}{c}0,3 \pm \\
0,1\end{array}$ & $\begin{array}{c}0,17 \pm \\
0,01\end{array}$ & $\begin{array}{c}0,8 \pm \\
0,1\end{array}$ & $0,9 \pm 0,1$ & $\begin{array}{c}0,50 \pm \\
0,03\end{array}$ & $\begin{array}{c}1,53 \pm \\
0,04\end{array}$ & $\begin{array}{c}1,11 \pm \\
0,01\end{array}$ & $\begin{array}{c}0,27 \pm \\
0,01\end{array}$ & $0,5^{1}$ \\
\hline $\mathbf{C u}$ & $\begin{array}{c}0,012 \pm \\
0,005\end{array}$ & $\begin{array}{c}0,5 \pm \\
0,1\end{array}$ & $\begin{array}{c}0,20 \pm \\
0,04\end{array}$ & $\begin{array}{c}0,3 \pm \\
0,1\end{array}$ & $\begin{array}{c}0,25 \pm \\
0,03\end{array}$ & $\begin{array}{c}1,3 \pm \\
0,1\end{array}$ & 0,1 & $\begin{array}{c}0,5 \pm \\
0,2\end{array}$ & $\begin{array}{c}1,3 \pm \\
0,4\end{array}$ & $\begin{array}{c}1,13 \pm \\
0,04\end{array}$ & $\begin{array}{c}0,12 \pm \\
0,03\end{array}$ & $\begin{array}{l}0,5^{1} \\
1^{2,3}\end{array}$ \\
\hline $\mathbf{F e}$ & $\begin{array}{c}0,8 \pm \\
0,1\end{array}$ & $\begin{array}{c}1,2 \pm \\
0,1\end{array}$ & $\begin{array}{c}2,3 \pm \\
0,2\end{array}$ & $5 \pm 1$ & $\begin{array}{c}3,3 \pm \\
0,1\end{array}$ & 3 & 2 & $=1$ & \pm 3 & \pm 4 & $\begin{array}{c}85,3 \pm \\
0,3\end{array}$ & $\begin{array}{c}10^{1} \\
15^{2,3}\end{array}$ \\
\hline Mn & $\begin{array}{c}0,50 \pm \\
0,07\end{array}$ & $4 \pm 1$ & $\begin{array}{c}1,3 \pm \\
0,1\end{array}$ & $\begin{array}{c}1,6 \pm \\
0,3\end{array}$ & $\begin{array}{c}1,6 \pm \\
0,1\end{array}$ & $\begin{array}{c}3,0 \pm \\
0,3\end{array}$ & $5 \pm 1$ & $\begin{array}{c}5,8 \pm \\
0,1\end{array}$ & $\begin{array}{c}18,6 \pm \\
0,7\end{array}$ & $\begin{array}{c}4,5 \pm \\
0,1\end{array}$ & $\begin{array}{c}6,0 \pm \\
0,1\end{array}$ & $\begin{array}{c}1^{1} \\
1^{2,3}\end{array}$ \\
\hline $\mathbf{N i}$ & $\begin{array}{c}0,004 \pm \\
0,001\end{array}$ & $\begin{array}{c}0,5 \pm \\
0,1\end{array}$ & $\begin{array}{c}0,2 \pm \\
0,1\end{array}$ & $\begin{array}{c}0,4 \pm \\
0,1\end{array}$ & $\begin{array}{c}0,3 \pm \\
0,1\end{array}$ & $\begin{array}{c}0,9 \pm \\
0,1\end{array}$ & $1,1 \pm 0,1$ & $\begin{array}{c}0,70 \pm \\
0,03\end{array}$ & $\begin{array}{c}1,8 \pm \\
0,1\end{array}$ & $\begin{array}{c}1,39 \pm \\
0,02\end{array}$ & $\begin{array}{c}0,4 \pm \\
0,1\end{array}$ & $2^{2}$ \\
\hline Zn & $\begin{array}{c}0,57 \pm \\
0,02\end{array}$ & $\begin{array}{c}3,3 \pm \\
0,1\end{array}$ & $\begin{array}{c}0,9 \pm \\
0,2\end{array}$ & $\begin{array}{c}1,1 \pm \\
0,4\end{array}$ & $\begin{array}{c}1,3 \pm \\
0,3\end{array}$ & $\begin{array}{c}4,1 \pm \\
0,4\end{array}$ & ,3 & $3 \pm 1$ & $\begin{array}{c}4,3 \pm \\
0,1\end{array}$ & $\begin{array}{c}5,3 \pm \\
0,1\end{array}$ & $\begin{array}{c}3,0 \pm \\
0,3\end{array}$ & $5^{2}$ \\
\hline
\end{tabular}

${ }^{1}$ Resolução CONSEMA 355/2017 (CONSEMA, 2017); ${ }^{2}$ Resolução CONAMA 430/2011 (BRASIL, 2011); ${ }^{3}$ Fração dissolvida para Resolução CONAMA 430/2011

A Fase I (dias 1-115) apresentou a maior quantidade de dias de operação, para que houvesse a estabilização do reator como objetivo de investigar a suplementação dos metais $\mathrm{Co}, \mathrm{Cu}, \mathrm{Fe}, \mathrm{Mn}$, $\mathrm{Ni}$ e $\mathrm{Zn}$ em fases estacionárias de desempenho. As concentrações dos metais na Fase I, portanto, podem ser provindas da vinhaça que foi adicionada ao reator como doador de elétrons e fonte de carbono (Tabela 1).

$\mathrm{Na}$ Tabela 2 estão apresentadas as concentrações efluentes dos metais $\mathrm{Co}, \mathrm{Cu}$, $\mathrm{Fe}, \mathrm{Mn}, \mathrm{Ni}$ e $\mathrm{Zn}$, comparados com valores máximos permitidos para emissão (lançamento) de efluentes líquidos estabelecidos pelas legislações vigentes.

As concentrações efluentes de cobalto foram comparadas com a Resolução CONSEMA 357/2017 por não conter tal metal na legislação nacional (CONAMA 430/2011). Já as concentrações de cobre, ferro e manganês foram comparadas também com a Resolução CONSEMA por prever as frações totais para estes metais, uma vez que a legislação nacional prevê somente as frações dissolvidas.

As concentrações dos metais $\mathrm{Co}, \mathrm{Cu}$, $\mathrm{Ni}$ e $\mathrm{Zn}$ apresentaram valores abaixo do limite permitido pelas legislações vigentes durante todo o período de operação do reator, exceto algumas concentrações pontuais no $223^{\circ}$ dia. Para ferro, as concentrações dos efluente tratado apresentaram valores abaixo do limite permitido na maior parte do tempo de operação do reator, mesmo que as concentrações suplementadas deste metal foram as maiores em relação aos demais analitos (110 mg. $\left.\mathrm{L}^{-1}\right)$. E para manganês, comumente de mais difícil remoção e mesmo com eficiências de remoção relativamente inferiores aos demais metais, alguns valores de suas concentrações efluente apresentam valores inferiores aos valores máximos permitidos. Portanto para o presente estudo, a caracterização dos efluentes comprovou a eficácia do tratamento biológico da DAM sintética (com suplementações de metais baseandose nas mais altas concentrações de metais encontradas na literatura) para a remoção de todos os metais descritas detalhadamente a seguir.

As eficiências de remoção dos metais, na Fase I, foram 67, 61, 87, 7, 39 e $67 \%$, respectivamente, para $\mathrm{Co}, \mathrm{Cu}, \mathrm{Fe}, \mathrm{Mn}, \mathrm{Ni}$ e Zn. A partir do início da suplementação dos metais (Fase II) até o final de operação do reator (Fase IV) ocorreram as maiores remoções dos metais $\mathrm{Co}, \mathrm{Cu}, \mathrm{Ni}$ e $\mathrm{Zn}$ com eficiências de remoção médias (média das Fases II, III e IV) iguais a $90 \pm 6,86 \pm 8$, $91 \pm 3$ e $84 \pm 7$, respectivamente (Figura 1, 
Tabela 3).

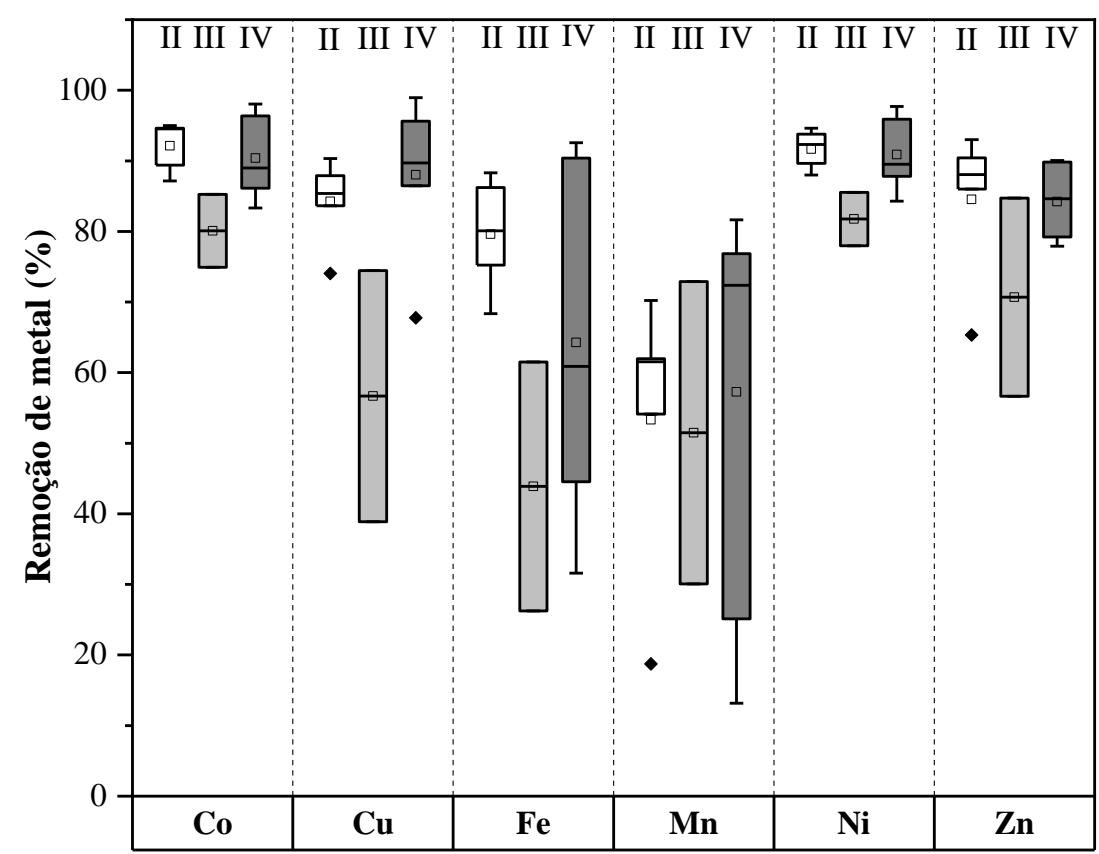

Figura 1. Eficiência de remoção dos metais $\mathrm{Co}, \mathrm{Cu}, \mathrm{Fe}, \mathrm{Mn}$, Ni e Zn

Tabela 3. Principais resultados determinados para cada fase operacional

\begin{tabular}{ccccccc}
\hline Fase & I & II & III & IV & $\begin{array}{c}\text { Média } \\
\text { fases II, } \\
\text { III e IV }\end{array}$ & $\begin{array}{c}\text { Média } \\
\text { total }\end{array}$ \\
& & & & & $90 \pm 6$ & $88 \pm 8$ \\
\hline Remoção de Co (\%) & 67 & $92 \pm 4$ & $80 \pm 7$ & $90 \pm 5$ & $90 \pm 0$ \\
Remoção de Cu (\%) & 61 & $84 \pm 6$ & $73 \pm 2$ & $91 \pm 5$ & $86 \pm 8$ & $84 \pm 10$ \\
Remoção de Fe (\%) & 87 & $80 \pm 8$ & $70 \pm 11$ & $70 \pm 24$ & $73 \pm 18$ & $74 \pm 18$ \\
Remoção de Mn (\%) & 7 & $53 \pm 20$ & $79 \pm 9$ & $59 \pm 28$ & $60 \pm 24$ & $56 \pm 26$ \\
Remoção de Ni (\%) & 39 & $92 \pm 3$ & $87 \pm 2$ & $92 \pm 4$ & $91 \pm 3$ & $86 \pm 14$ \\
Remoção de Zn (\%) & 67 & $85 \pm 11$ & $80 \pm 6$ & $86 \pm 4$ & $84 \pm 7$ & $83 \pm 8$ \\
\hline
\end{tabular}

Resultados semelhantes foram apresentados por Bekmezci et al. (2011) que obtiveram remoções de $99 \%$ para os metais $\mathrm{Co}, \mathrm{Cu}$ e $\mathrm{Ni}$. Alguns autores reportaram relação proporcional entre a concentração de metal afluente e a sua eficiência de remoção de acordo com a solubilidade intrínseca de cada metal (ÜSTÜN, 2009; OLIVEIRA et al., 2007; BUSETTI et al., 2005; CHIPASA, 2001). Elementos como $\mathrm{Cu}$ e $\mathrm{Fe}$ que exibiram expressiva eficiência de remoção apresenta $\mathrm{pH}$ de hidrólise (valor específico de $\mathrm{pH}$, acima do qual o elemento não é mais encontrado na forma ionizada sem complexação) entre 4 e 6, fator contribuinte para a remoção destes metais uma vez que a faixa de $\mathrm{pH}$ afluente foi de 4,1 a 5,3 (CAMPANER \& SILVA, 2009).

A eficiência de remoção média de $\mathrm{Fe}$ no presente estudo $(74 \pm 18 \%$, Figuras 1 e 
2), tem valores similares ao apresentado por Godoi et al. (2017) que analisaram a remoção do $\mathrm{Fe}$ com concentrações variando de 50 a $400 \mathrm{mg} \mathrm{L}^{-1}$ com remoção de Fe superiores a $80 \%$ (neste estudo $88 \%$ na Fase II). De la Varga et al. (2013), atribuiu a alta remoção de $\mathrm{Fe}$ à alta solubilidade dos óxidos de $\mathrm{Fe}$, em condições anaeróbias, que são precipitados em sulfetos de Fe.

Até o $126^{\circ}$ dia de operação do reator, as eficiências de remoção de manganês exibiram variações de 7 a $18 \%$ (Figura 2). Tais valores foram similares aos dados relatados por Barbosa et al. (2014) que obtiveram baixa remoção de $\mathrm{Mn}$, em experimento batelada, de apenas $27 \%$ quando a concentração inicial era de 1,5 mg.L $\mathrm{L}^{-1}$. Outros autores também atribuem a baixa eficiência de remoção de $\mathrm{Mn}$ à interação complexa deste metal (com produto de solubilidade - $\mathrm{K}_{\mathrm{PS}}$ superior aos outros analitos) aliada ao fator preocupante de haver altas concentrações de $\mathrm{Mn}$ em DAMs (BEKMEZCI et al., 2011, KRÖPFELOVÁ et al., 2009). Diferentemente das baixas eficiências observadas para remoção de Mn por processos físico-químicos, o processo biológico apresentou eficiências de até 85 $\%$ e eficiência de remoção média de $56 \pm$ $24 \%$, para concentrações de Mn próximas às encontradas em DAMs. A alta eficiência de remoção de Mn pode ser explicada devido à interação com o metal $\mathrm{Fe}$, uma vez que a precipitação de Fe facilita a remoção de Mn presente em solução por co-precipitação biológica (YOO et al., 2010) evidenciado a partir do $120^{\circ}$ dia de operação do reator, quando o decréscimo na remoção de ferro ocorre de forma concomitante à remoção de manganês (Figura 2).

A análise estatística dos dados referentes às eficiências de remoção dos metais $\mathrm{Co}, \mathrm{Cu}, \mathrm{Fe}, \mathrm{Mn}, \mathrm{Ni}, \mathrm{Fe}$ e $\mathrm{Zn}$, indicaram que durante as Fases II, III e IV (nas quais houve a suplementação dos metais) não foram encontradas diferenças significativas $(\mathrm{p}=0,811 ;<0,05)$. Considerando a Fase I (sem suplementação de metais) em comparação com as três fases seguintes, houve diferença significativa entre as fases $(p=0,0417 ;>$

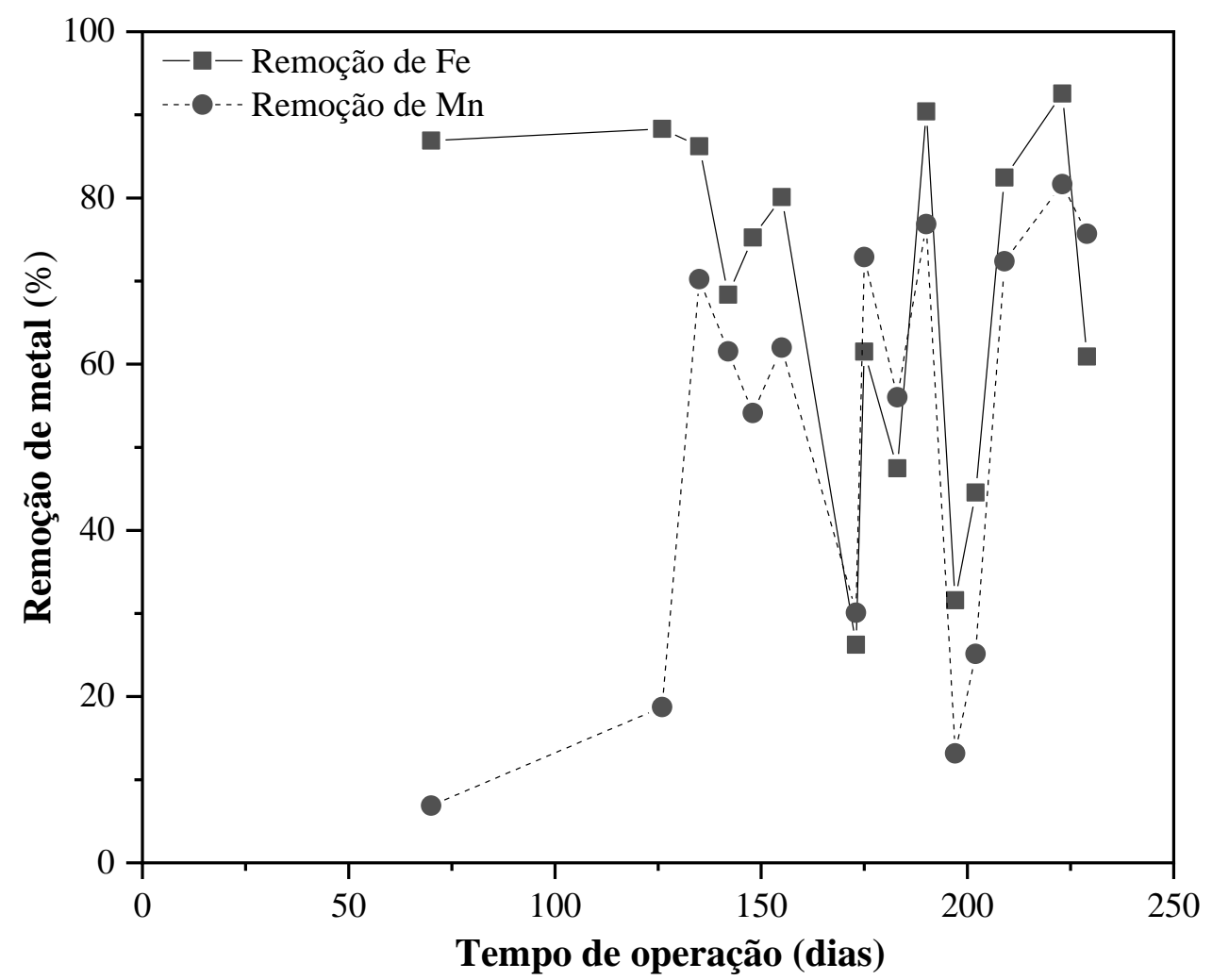

Figura 2. Remoção de ferro e manganês ao longo do tempo de operação do reator 
$0,05)$ o que era esperado, uma vez que as concentrações dos metais foram dosadas no desenho experimental.

Através do processo da sulfetogênese, as BRS presentes no tratamento anaeróbio são fundamentais para promover a redução de sulfato (que estão presentes em altas concentrações nas DAMs) contribuindo com a elevação do $\mathrm{pH}$ e formando sulfetos que por sua vez reagem com metais (sulfetos metálicos - MeS) e formam precipitados insolúveis rapidamente.

No presente estudo, a sulfetogênese propiciou a redução de sulfato em solução (eficiências de remoção de sulfato entre 55 e $90 \%$ ), concomitante à elevação da faixa de $\mathrm{pH}$ efluente para 6,4 - 7,4 (com variações no $\mathrm{pH}$ afluente de 4,1 a 5,3) e o decréscimo na toxicidade dos metais (objetivo do presente estudo). Ademais, é preciso levar em conta que tais BRS competem com diferentes grupos microbianos (acetogênicas e metanogênicas), tornando $\mathrm{o}$ ambiente anaeróbio complexo do ponto de vista físico, químico e biológico (BARBOSA et al., 2014). A magnitude dessa competição pode estar intimamente relacionada ao $\mathrm{pH}$, ocorrendo variações no $\mathrm{pH}$, caso não haja correções desse parâmetro via adição de ácido/base (CHERNICHARO, 1997).

Mesmo com a variação do $\mathrm{pH}$ durante a operação do reator tratando DAM sintética, condições químicas propícias foram estabelecidas para promover a remoção de metais por precipitação. Estudos reportam que $\mathrm{Cu}, \mathrm{Fe}$, Ni e $\mathrm{Zn}$ foram precipitados em soluções com $\mathrm{pH}$ menores de 7 (AUBÉ \& ZINCK, 2003, KURNIAWAN et al., 2006). Este fato também foi confirmado com a avaliação dos metais $\mathrm{Co}, \mathrm{Cu}, \mathrm{Fe}, \mathrm{Mn}, \mathrm{Ni}$ e $\mathrm{Zn}$ nas amostras de descarte de fundo, que correspondem à precipitação dos metais e estão presentes no lodo (Tabela 4).

Os elevados valores de concentrações dos metais presentes nas amostras de descarte de fundo comprovam $o$ desempenho robusto do reator relativo à remoção/precipitação de metais ao longo do período operacional. A retirada do lodo, com metais concentrados, periodicamente foi necessária para reduzir o potencial tóxico dos metais sobre a biomassa, afetando o desempenho do bioprocesso, interferindo no equilíbrio químico das espécies e fluxo dos precipitados (GALLEGOS-GARCIA et al., 2009). As retiradas esporádicas do descarte de fundo (ocorridas por exemplo, no $130^{\circ}, 160^{\circ} \mathrm{e}$ $180^{\circ}$ dia de operação do reator) comprovaram a afirmação anterior principalmente para Fe e Mn, pois ocorrem decréscimos nas remoções destes metais anteriormente às coletas, e posterior, recuperação nas referidas remoções

Tabela 4. Concentrações dos metais $\mathrm{Co}, \mathrm{Cu}, \mathrm{Fe}, \mathrm{Mn}, \mathrm{Ni}$ e $\mathrm{Zn}\left(\mathrm{mg}^{\mathrm{L}} \mathrm{L}^{-1}\right)$ nas amostras de descarte de fundo do reator

\begin{tabular}{ccccccc}
\hline $\begin{array}{c}\text { Dia de } \\
\text { operação } \\
\text { do reator }\end{array}$ & Co & $\mathbf{C u}$ & $\mathbf{F e}$ & $\mathbf{M n}$ & $\mathbf{N i}$ & $\mathbf{Z n}$ \\
\hline $\mathbf{1 3 8}$ & $6737 \pm 1079$ & $5750 \pm 929$ & $79775 \pm 11055$ & $1463 \pm 247$ & $8590 \pm 1369$ & $4098 \pm 629$ \\
$\mathbf{1 4 2}$ & $2525 \pm 204$ & $1961 \pm 231$ & $32300 \pm 3659$ & $474 \pm 56$ & $3314 \pm 262$ & $3012 \pm 238$ \\
$\mathbf{1 5 5}$ & $1036 \pm 310$ & $894 \pm 234$ & $18774 \pm 4978$ & $180 \pm 47$ & $1394 \pm 414$ & $3524 \pm 1008$ \\
$\mathbf{1 5 8}$ & $962 \pm 381$ & $353 \pm 112$ & $31629 \pm 8727$ & $355 \pm 107$ & $1577 \pm 619$ & $1447 \pm 564$ \\
$\mathbf{1 6 3}$ & $941 \pm 378$ & $566 \pm 323$ & $40805 \pm 22874$ & $464 \pm 256$ & $1446 \pm 578$ & $1536 \pm 609$ \\
$\mathbf{1 7 0}$ & $1627 \pm 228$ & $940 \pm 176$ & $45776 \pm 8140$ & $511 \pm 92$ & $2224 \pm 312$ & $3642 \pm 495$ \\
$\mathbf{1 7 5}$ & $1119 \pm 309$ & $824 \pm 303$ & $43942 \pm 14128$ & $372 \pm 131$ & $1791 \pm 493$ & $3151 \pm 494$ \\
$\mathbf{1 8 3}$ & $1843 \pm 461$ & $2071 \pm 566$ & $38301 \pm 9229$ & $271 \pm 67$ & $2257 \pm 563$ & $5887 \pm 1369$ \\
\hline
\end{tabular}


(Figura 2).

Apesar das quedas pontuais de eficiência de remoção dos metais ao longo do período de operação do reator, a configuração do reator DFSBR despontouse de forma promissora ao promover a precipitação de compostos metálicos, originando um lodo rico em metais e que podem ser recuperados para utilização em outros processos industriais (SÁNCHEZ et al., 2013). A contribuição do tratamento

\section{CONCLUSÕES}

A partir dos resultados obtidos com o monitoramento das concentrações afluentes, efluentes e de descarte de fundo de $\mathrm{Co}, \mathrm{Cu}, \mathrm{Fe}, \mathrm{Mn}$, Ni e $\mathrm{Zn}$ em amostras de drenagem ácida de mina sintética sujeitas ao tratamento anaeróbio com suplementação de matéria orgânica e de metais, foi possível observar que o reator anaeróbio de leito fixo estruturado e fluxo descendente é extremamente eficiente para promover a remoção de metais. As eficiências médias de remoção, nas Fases de II a IV, foram $92 \pm 4,87 \pm 8,71 \pm 21$, $61 \pm 24,92 \pm 4$ e $86 \pm 8$ para os metais Co, $\mathrm{Cu}, \mathrm{Fe}, \mathrm{Mn}, \mathrm{Ni}$ e $\mathrm{Zn}$, respectivamente. As altas eficiências de remoção do metal Mn indicam que o tratamento anaeróbio de DAM é eficaz, visto que processos físicoquímicos comumente empregados (que exigem meio fortemente oxidante, $\mathrm{pH}$ elevado e interação com outros íons como o Fe para sua devida remoção) não atingem eficiências de remoção como as encontradas neste estudo. Para as concentrações afluentes máximas de 14, 11, 218, 25, 17 e $30 \mathrm{mg} . \mathrm{L}^{-1}$ para $\mathrm{Co}, \mathrm{Cu}$, $\mathrm{Fe}, \mathrm{Mn}, \mathrm{Ni}$ e $\mathrm{Zn}$, respectivamente, os metais foram removidos na forma de

\section{REFERÊNCIAS BIBLIOGRÁFICAS}

AKCIL, A.; KOLDAS, S. Acid mine drainage (AMD): causes, treatment and case studies. Journal of Cleaner Production, v. 14: 1139-1145, 2006.

$\begin{array}{llr}\text { AMERICAN } & \text { PUBLIC } & \text { HEALTH } \\ \text { ASSOCIATION } & \text { (APHA); AMERICAN } \\ \text { WATER WORKS ASSOCIATION }\end{array}$

anaeróbico vai além da remoção dos metais, uma vez que as BRS contribuíram também para a redução do sulfato e da acidez do meio, e podem ser mais econômicas e eficazes do que o controle do pH e posterior precipitação dos metais via processos físico-químicos. Tais parâmetros são fundamentais e enquadrados nas legislações vigentes para o correto descarte desse tipo complexo de efluente.

sulfetos metálicos ou, caso não fossem precipitados, os valores das concentrações dos metais já se encontram inferiores e enquadrados nas legislações vigentes. $\mathrm{O}$ desempenho da sulfetogênese foi adequado em todas as fases do estudo, indicando que as ordens de concentrações de metais e da vinhaça adicionada (Fase I) permitiram manter o processo. A precipitação de metais com sulfeto colaborou para retirada de substâncias que conferem toxicidade aos organismos. A contribuição do tratamento anaeróbico vai além da remoção dos metais, uma vez que as BRS contribuíram também para a redução do sulfato e da acidez do meio, e podem ser mais econômicas e eficazes do que $o$ controle do $\mathrm{pH}$ e posterior precipitação dos metais via processos físico-químicos.

\section{AGRADECIMENTOS}

Agradecemos à Fundação de Amparo à Pesquisa do Estado de São Paulo (Processos FAPESP: 2015/06246-7 e 2016/24526-0) e ao Conselho Nacional de Desenvolvimento Científico e Tecnológico (Processo CNPq: 303469/2017-0) pelo suporte financeiro.

(AWWA); WATER ENVIRONMENT FEDERATION (WEF); EATON, A.D. Standard Methods for the Examination of Water and Wastewater. $21^{\text {st }}$ ed. Washington: APHA/AWWA/WEF, 2005.

AUBÉ, B.; ZINCK, J. Lime treatment of acid mine drainage in Canada. In: Juliano, 
P.B.; Paulo, S.M.S.; Dixon, B.; Bryan, Tisch (Eds.). Brazil-Canada Seminar on Mine Rehabilitation Technological Innovations. Rio de Janeiro: Desktop Publishing, 2003.

BAKER, B. J.; BANFIELD, J. F. Microbial communities in acid mine drainage. FEMS Microbiology Ecology, v. 44: 139-152, 2003.

BARBOSA, L. P.; COSTA, P. F.; BERTOLINO, S. M.; SILVA, J. C. C.; GUERRA-SÁ, R.; LEÃO, V. A.; TEIXEIRA, M. C. Nickel, manganese and copper removal by a mixed consortium of sulfate reducing bacteria at a high COD/sulfate ratio. World Journal of Microbiology and Biotechnology, v. 30: 2171-2180, 2014.

BEKMEZCI, O. K.; UCAR, D.; KAKSONEN, A. H.; SAHINKAYA, E. Sulfidogenic biotreatment of synthetic acid mine drainage and sulfide oxidation in anaerobic baffled reactor. Journal of Hazardous Materials, v. 189(3): 670-676, 2011.

BENSON, N. U.; ANAKE, W. U.; OLANREWAJU, I. O. Analytical Relevance of Trace Metal Speciation in Environmental and Biophysicochemical Systems, American Journal of Analytical Chemistry, v. 4: 633-641, 2013.

BLOWES, D. W.; PTACEK, J.; LAMBOR, J. L.; WEISENER, C. G. The geochemistry

of acid mine drainage. In: HOLLAND, $\mathrm{H}$. D.; TUREKIAN, K. K. Treatise on geochemistry. Amsterdan: Elsevier B.V., v. 9: 149-204, 2003.

BRASIL. Ministério do Meio Ambiente. Conselho Nacional de Meio Ambiente (CONAMA). Resolução $n^{\circ}$ 430, de 13 de maio de 2011. Dispõe sobre as condições e padrões de lançamento de efluentes. Diário Oficial da União, Brasília, DF, 13 mai. 2011. Disponível em: http://www.mma.gov.br/port/conama/legia bre.cfm?codlegi=646. Acesso em 09 Out. 2020.
BUSETTI, F.; BADOER, S.; CUOMO, M., RUBINO, B.; TRAVERSO, P. Occurrence and Removal of Potentially Toxic Metals and Heavy Metals in the Wastewater Treatment Plant of Fusina (Venice, Italy). Industrial \& Engineering Chemistry Research, v. 44: 9264-9272, 2005.

CAMPANER, V. P.; SILVA, W. L. Processos físico químicos em drenagem ácida de minas em mineração de carvão do sul do Brasil. Química Nova, v. 32: 146152, 2009.

CAMPANER, V. P., LUIZ-SILVA, W.; MACHADO, W. (2014). Geochemistry of acid mine drainage from a coal mining area and processes controlling metal attenuation in stream waters, southern Brazil. Anais da Academia Brasileira de Ciências, v. 86(2):539-554, 2014.

CAMPBELL, P. G. C. Interactions between trace metals and organisms: A critique of the free-ion activity model. In: Tessier, A.; Turner, D. (Eds.) Metal Speciation and Bioavailability in Aquatic Systems. Chichester (UK): J. Wiley \& Sons, 1995.

CÁNOVAS, C. R.; RIERA, J.; CARRERO, S.; OLÍAS, M. Dissolved and particulate metal fluxes in an AMDaffected stream under different hydrological conditions: The Odiel River (SW Spain). Catena, v. 165: 414-424, 2018.

CASTRO NETO, E. S.; AGUIAR, A. B. S.; RODRIGUEZ, R. P.; SANCINETTI, G. P. Acid Mine Drainage Treatment and Metal Removal based on a Biological Sulfate-Reducing Process. Brazilian Journal of Chemical Engineering, v. 35(2): 543-552, 2018.

CHERNICHARO, C. A. L. Reatores anaeróbios. Princípios do tratamento biológico de águas residuárias. $2^{\mathrm{a}}$ ed. Belo Horizonte: Departamento de Engenharia Sanitária e AmbientalUniversidade Federal de Minas Gerais, 1997. 
CHIPASA, K. B. Accumulation and fate of selected heavy metals in a biological wastewater treatment system. Waste Management, v. 23: 135-143, 2003.

Conselho Estadual Do Meio Ambiente. (CONSEMA). Resolução no 355 de 19 de julho de 2017. Critérios e padrões de emissão de efluentes líquidos para as fontes geradoras que lancem seus efluentes em águas superficiais no Estado do Rio Grande do Sul. Disponível em: https://www.sema.rs.gov.br/upload/arquivo s/201707/19110149-355-2017-criterios-epadroes-de-emissao-de-efluentes-

liquidos.pdf. Acesso em: 09 out. 2020.

DIMPE, K. M.; NGILA, J. C.; MABUBA, N.; NOMGONGO, P. N. Evaluation of sample preparation methods for the detection of total metal content using inductively coupled plasma optical emission spectrometry (ICP-OES) in wastewater and sludge. Physics and Chemistry of the Earth, v. 76-78: 42-48, 2014.

DAMIANOVIC, M. H. R. Z.; FORESTI, E. Anaerobic degradation of synthetic wastewaters at different levels of sulfate and COD/Sulfate ratios in horizontal-flow anaerobic reactors (HAIB). Environmental Engineering Science, v. 24(3): 383-393, 2007.

FALAGÁN, C.; GRAIL, B. M.; JOHNSON, D. B. New approaches for extracting and recovering metals from mine tailings. Minerals Engineering, v. 106: 71-78, 2017.

GALLEGOS-GARCIA, M.; CELIS, L. B.; RANGEL-MÉNDEZ, R.; RAZOFLORES, E. Precipitation and recovery of metal sulfides from metal containing acidic wastewater in a sulfidogenic down-flow fluidized bed reactor. Biotechnology and Bioengineering, v. 102(1): 91-99, 2009.

GARCIA, C.; MORENO, D. A.; BALLESTER, A.; BLÀZQUZ, M. L.; GONZÁLEZ, F. Bioremediation of an industrial acid mine water by metaltolerant sulphate-reducing bacteria.
Minerals Engineering, v. 14(9): 9971008, 2001.

GINÉ-ROSIAS, M. F. Espectrometria de Emissão Atômica com Plasma Acoplado Indutivamente (ICP-AES), Piracicaba: CENA, 1998.

GODOI, L. A. G.; FORESTI, E.; DAMIANOVIC, M. H. R. Z. Down-flow fixed-structured bed reactor: An innovative reactor configuration applied to acid mine drainage treatment and metal recovery. Journal of Environmental Management, v. 197: 597-604, 2017.

HARRIS, D. C. Dissolving Samples for Analysis, in: Quantitative Chemical Analysis. New York: W. H. Freeman and Company, 2007.

HAO, T.; XIANG, P.; MACKEY, H. R.; CHI, K.; LU, H.; CHUI, H.; VAN LOOSDRECHT, M. C. M.; CHEN, G-H. A review of biological sulfate conversions in wastewater treatment. Water Research, v. $65: 1-21,2014$.

HU, Y.; JING, Z.; SUDO, Y.; NIU, Q.; DU, J.; WU, J.; LI, Y. Y. Effect of influent $\mathrm{COD} / \mathrm{SO}_{4}{ }^{2-}$ Ratios on UASB treatment of a synthetic sulfate containing wastewater. Chemosphere, v. 130: 24-33, 2015.

JOHNSON, D. B.; HALLBERG, K. B. Acid mine drainage remediation options: a review. Science of the Total Environment, v. 338: 3-14, 2005.

KAKSONEN, A. H.; PUHAKKA, J. A. Sulfate reduction-based process for the treatment of acid mine drainage and the recovery of metals. Engineering in Life Science, v. 7(6): 541-564, 2007.

KEFENI, K. K.; MSAGATI, T. A. M.; MAMBA, B. B. Acid mine drainage: Prevention, treatment options, and resource recovery: A review. Journal of Cleaner Production, v. 151: 475-493, 2017.

KRÖPFELOVÁ, L.; VYMAZAL， J.; SVEHLA, J.; STÍCHOVÁ, J. Removal of trace elements in three horizontal subsurface flow constructed wetlands in the Czech Republic. Environmental Pollution, v. 157: 1186-1194, 2009. 
KRUG, F. J.; ROCHA, F. R. P. Métodos de preparo de amostras para análise elementar. (Orgs.), São Paulo: EditSBQ, v. 1, 2016.

KURNIAWAN, T. A.; CHAN, G. Y. S.; LO, W. H.; BABEL, S. 2006. Physicochemical treatment techniques for wastewater laden with heavy metals. Chemical Engineering Journal, v. 118: 83-98, 2006.

LEWIS, A. E. Review of metal sulphide precipitation. Hydrometallurgy, v. 104, p. 222-234, 2010.

MELlO, J. W. V.; DUARTE, H. A.; LADEIRA, A. C. Q. Origem e Controle do Fenômeno Drenagem Ácida de Mina. Cadernos Temáticos de Química Nova na Escola, v. 8: 24-29, 2014.

NOGUEIRA, E. W.; GODOI, L. A. G.; BRUCHA, G.; DAMIANOVIC, M. H. R. $Z$. Tratamento de drenagem ácida de minas sintética utilizando reator anaeróbio de leito fixo-estruturado e fluxo descendente (DFSBR). In: Anais II Seminário do Projeto Temático Aplicação do conceito biorrefinaria a estações tratamento biológico águas residuárias o controle da poluição ambiental aliado à recuperação matéria e energia, São Carlos/SP, 2018, p. 346-354.

$\begin{array}{llccc}\text { OLIVEIRA, } & \text { A. } & \text { S.; } & \text { BOCIO, } & \text { A.; } \\ \text { TREVILATO, } & \text { T. } & \text { M. } & \text { B.; }\end{array}$ TAKAYANAGUI, A. M. M.; DOMINGO, J. L.; SEGURA-MUÑOZ, S. I. Heavy Metals in Untreated/Treated Urban Effluent and Sludge from a Biological Wastewater Treatment Plant. Environmental Science and Pollution Research, v. 14(7): 483-489, 2007.

SÁNCHEZ-ANDREA, I.; STAMS, A. J. M.; AMILS, R.; SANZ, J. L. Enrichment and isolation of acidophilic sulfate-reducing bacteria from Tinto River sediments. Environmental Microbiology Reports, v. 5(5): 672-678, 2013.

SANTOS, A. L.; JOHNSON, D. B. The effects of temperature and $\mathrm{pH}$ on the kinetics of an acidophilic sulfidogenic bioreactor and indigenous microbial communities. Hydrometallurgy, v. 168: 116-120, 2017.

SAHINKAYA, E.; GUNGOR, M. Comparison of sulfidogenic up-flow and down-flow fluidized-bed reactors for the biotreatment of acidic metal-containing wastewater. Bioresource Technology, v. 101: 9508-9514, 2010.

SHEORAN, A. S.; SHEORAN, V.; CHOUDHARY, R. P. Bioremediation of acid- rock drainage by sulfate-reducing prokaryotes: A review. Minerals Engineering, v. 23: 1073-1100, 2010.

UCAR, D.; BEKMEZCI, O. K.; KAKSONEN, A. H.; SAHINKAYA, E. Sequential precipitation of $\mathrm{Cu}$ and $\mathrm{Fe}$ using a three-stage sulfidogenic fluidized-bed reactor system. Minerals Engineering, v. 24(11): 1100-1105, 2011.

ÜSTÜN, G. E. Occurrence and removal of metals in urban wastewater treatment plants. Journal of Hazardous Materials, v. 172: 833-838, 2009.

DE LA VARGA, D.; DÍAZ, M.A.; RUIZ, I.; SOTO, M. Heavy metal removal in an UASB-CW system treating municipal wastewater. Chemosphere, v. 93: 13171323, 2013.

VILELA, R. S.; DAMIANOVIC, M. H. R. Z.; FORESTI, E. Removing organic matter from sulfate-rich wastewater via sulfidogenic and methanogenic pathways. Water Science \& Technology, v. 69(8): 1669-1675, 2014.

Yoo, K.; Hiroyoshi, N.; Tsunekawa, M. Removal of Mn Ions by Biological Coprecipitation of $\mathrm{Fe}$ Ions, Geosystem Engineering, v. 13(3): p. 91-96, 2010.

ZHANG, C. Fundamentals of Environmental Sampling and Analysis, New Jersey: Wiley \& Sons, 2007. 